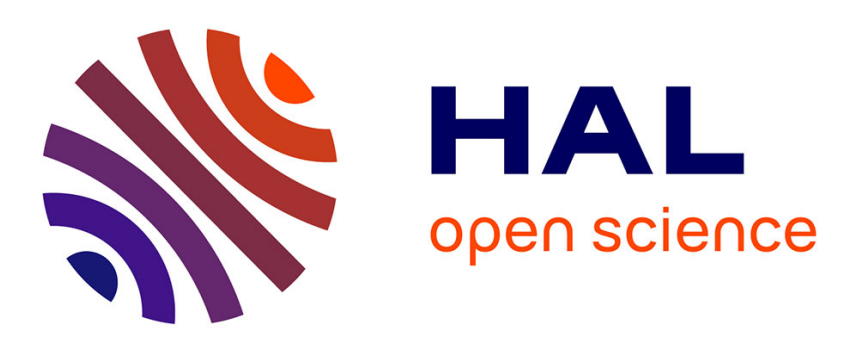

\title{
Effect of colony formation on light absorption by Botryococcus braunii
}

\author{
Jack Hoeniges, Razmig Kandilian, Chuanxin Zhang, Jeremy Pruvost, Jack \\ Legrand, Dominique Grizeau, Laurent Pilon
}

\section{To cite this version:}

Jack Hoeniges, Razmig Kandilian, Chuanxin Zhang, Jeremy Pruvost, Jack Legrand, et al.. Effect of colony formation on light absorption by Botryococcus braunii. Algal Research - Biomass, Biofuels and Bioproducts, 2020, 50, 10.1016/j.algal.2020.101985 . hal-03009153

\section{HAL Id: hal-03009153 \\ https://hal.science/hal-03009153}

Submitted on 17 Nov 2020

HAL is a multi-disciplinary open access archive for the deposit and dissemination of scientific research documents, whether they are published or not. The documents may come from teaching and research institutions in France or abroad, or from public or private research centers.
L'archive ouverte pluridisciplinaire HAL, est destinée au dépôt et à la diffusion de documents scientifiques de niveau recherche, publiés ou non, émanant des établissements d'enseignement et de recherche français ou étrangers, des laboratoires publics ou privés. 


\title{
Effect of colony formation on light absorption by Botryococcus braunii
}

\author{
Jack Hoeniges $^{\mathrm{a}}$, Razmig Kandilian ${ }^{\mathrm{a}, \mathrm{c}}$, Chuanxin Zhang ${ }^{\mathrm{b}}$, Jeremy Pruvost ${ }^{\mathrm{c}}$, Jack Legrand ${ }^{\mathrm{c}}$, \\ Dominique Grizeau ${ }^{\mathrm{c}}$, Laurent Pilon ${ }^{\mathrm{a}, *}$ \\ ${ }^{a}$ Mechanical and Aerospace Engineering Department, Henry Samueli School of Engineering and Applied Science, University of California, 420 Westwood Plaza, Los \\ Angeles, CA 90095, USA \\ ${ }^{\mathrm{b}}$ School of Energy Science and Engineering, Harbin Institute of Technology, 92 West Dashi Street, Harbin 150001, PR China \\ ${ }^{\mathrm{c}}$ Laboratoire de Génie des Procédés - Environnement - Agroalimentaire, Université de Nantes, CNRS, UMR 6144, 37 Boulevard de l'université, BP 406, Saint-Nazaire Cedex \\ 44602, France
}

\section{A R T I C L E I N F O}

\section{Keywords:}

Light transfer

Optical properties

Biodiesel

Photobioreactors

Absorption

\begin{abstract}
A B S T R A C T
This study elucidates the effect of colony formation on light absorption by Botryococcus braunii microalgae cells. The spectral average mass absorption cross-section of suspensions of $B$. braunii cultures with free-floating cells or colonies was measured experimentally across the photosynthetically active radiation region. The average mass absorption cross-section was found to decrease significantly across the spectrum in the presence of colonies. This observation could be attributed to (i) reduced pigment concentrations due to nutrient limitations, (ii) mutual shading of the aggregated cells, and/or (iii) the presence of the colonies' extracellular matrix. The Monte Carlo ray tracing method was used to elucidate the contribution of each of these phenomena on the mass absorption cross-section of cells in colonies. Colonies were modeled either as fractal aggregates of monodisperse cells or as an ensemble of monodisperse cells regularly arranged at the periphery of a hollow sphere embedded in a spherical extracellular matrix or as a volume and average projected area equivalent coated sphere. The change in pigment concentrations due to nutrient limitation was found to be the most important factor. In addition, the mass absorption cross-section of cells in colonies was found to decrease due to mutual shading among cells. This effect was stronger with increasing number of cells in the colony and increasing cell absorption index. The effect of extracellular matrix on the mass absorption cross-section was found to be negligible. Finally, good agreement was found between the equivalent coated sphere approximation and the colonies modeled as fractal aggregates comprised of monodisperse cells. This study also established that the Monte Carlo ray tracing method can be used for a variety of microalgae species and colony configurations, whose absorption cross-section are not readily calculated by standard methods due to their complex geometry, inhomogeneous nature, and large size compared to the wavelength of the incident light.
\end{abstract}

\section{Introduction}

Botryococcus braunii is a colony forming microalgae that has been widely studied for its potential integration into waste water treatment $[1,2]$, its capacity to produce antibacterial and antioxidant extracts [3-5], and its superior ability to produce hydrocarbons [1,6-13]. Indeed, $B$. braunii can achieve up to $75 \%$ of its dry weight in hydrocarbons, mainly located outside the cells in the colony extracellular matrix (ECM) $[6,8]$. In particular, the $B$ race of $B$. braunii produces hydrocarbon botryococcenes of the general formula $C_{n} H_{2 n-10}$ where $n$ ranges from 30 to 37 [10]. The ECM is a complex structure consisting of (i) rigid hydrocarbon polymers holding the cells in place, (ii) liquid hydrocarbons filling the intermediate space between the rigid hydrocarbons and the cells, and (iii) an extracellular polysaccharide (EPS) sheath surrounding the exterior of the colony [9,14]. Fig. 1 shows two micrographs of $B$. braunii race B cells from cultures grown for the present study featuring (a) single cells and (b) colonies.

In the above mentioned applications, $B$. braunii can be grown in various types of raceway ponds or photobioreactors (PBRs) exposed to sunlight, as the energy source, and fed with carbon dioxide, as the carbon source, while the medium contains nutrients (e.g., nitrates and phosphates) necessary to the growth of the microorganisms [15]. The raceway ponds and PBRs operated in the light-limited regime are not limited by any other operational parameters such as nutrients, $\mathrm{pH}$, and temperature. Then, productivity depends only on the amount and distribution of photons absorbed in the culture [16-18]. This is

\footnotetext{
* Corresponding author.

E-mail address: pilon@seas.ucla.edu (L. Pilon).
} 

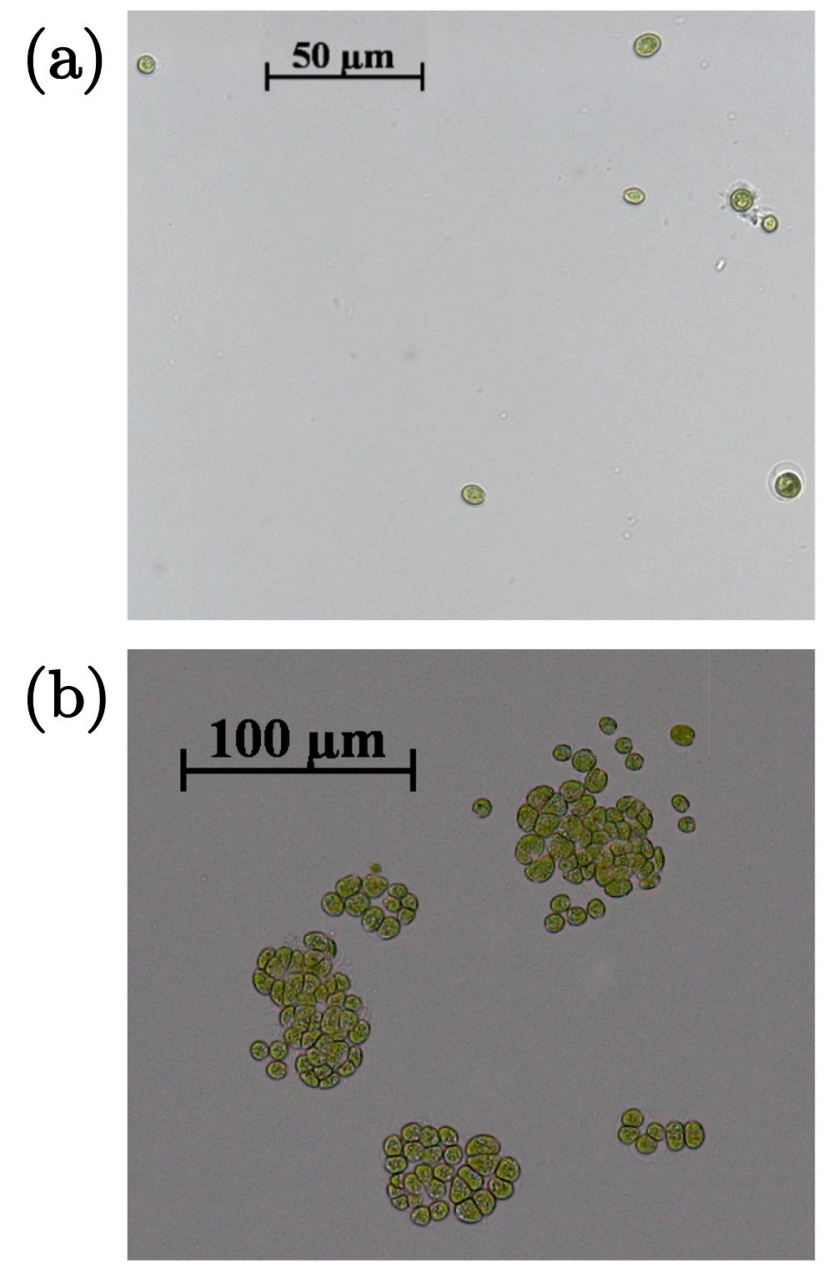

Fig. 1. Micrographs of B. braunii grown for this study as (a) single cells (Culture A) and (b) colonies resembling fractal aggregates (Culture B).

represented by the local rate of photon absorption (LRPA) at a given location in the culture expressed in $\mu \mathrm{mol}_{\mathrm{h} \nu} / \mathrm{kg} \mathrm{s}$ [16,19]. Predicting and controlling the LRPA in raceway ponds and PBRs is essential in order to maximize the growth rate and/or the production rate of the desired value-added product(s) [16]. Due to their large size compared with the wavelength of sunlight in the photosynthetically active radiation (PAR) region, microalgae cells and colonies are strongly forward scattering. Then, for a given culture configuration and biomass concentration, the LRPA depends entirely on the average mass absorption cross-section $\bar{A}_{a b s, \lambda}$ and on the incoming solar radiation flux [20,21]. This has been demonstrated theoretically and numerically for various PBR geometries [18]. Thus, measuring or predicting the mass absorption cross-section $\bar{A}_{a b s, \lambda}$ for the culture is sufficient to design and control raceway ponds and PBRs [16,21].

Moreover, the formation of $B$. braunii colonies may significantly affect light transfer in the culture via changes in the spectral mass absorption cross-section $\bar{A}_{a b s, \lambda}$ [22-24]. Indeed, Kandilian et al. [24] used the T-matrix method in the PAR region to simulate the effects of multiple scattering and shading among constituent monomers on the absorption and scattering cross-sections and asymmetry factor of fractal aggregates consisting of up to 1000 monomers with size parameter $x$ between 0.01 and 20 defined as $x=2 \pi r / \lambda$ where $r$ is the monomer radius and $\lambda$ is the radiation wavelength. In particular, mutual shading was found to cause the normalized absorption cross-section, defined as the ratio of the aggregate's absorption cross-section to the product of the number of individual particles in the aggregate and their absorption cross-section, to decrease monotonically with increasing number of strongly absorbing monomers. Similarly, Mulholland et al. [25] used the coupled electric and magnetic dipole method to study absorption and scattering by soot and silica particle agglomerates. For monomer size parameter $x>0.25$ the authors observed a decrease in the normalized absorption cross-section as monomer size parameter increased. This was attributed to the "shielding effect" among the constituent monomers. Liu and Mishchenko [26] used the superposition T-matrix method to study the optical cross-sections of soot and soot-containing aggregates. Polydisperse aggregates were comprised of soot, dust, and sulfate particles of size parameters $10,1.5$, and 3 , respectively. The optical cross-sections of such aggregates were smaller than their externally mixed values (i.e. widely separated with negligible particle interaction). The authors suggested that this decrease may be attributed to "mutual shadowing". Liu et al. [27,28] employed the generalized multi-sphere Mie-solution method (GMM) to study the effect of fractal prefactor and fractal dimension on the optical properties of soot aggregates. Here also, the authors observed a non-linear decrease in the normalized absorption cross-section of aggregates as a function of the number of monomers. This was attributed to the "shielding effect" and was found to be more pronounced for more compact aggregates characterized by large fractal prefactor and/or fractal dimension. Unfortunately, the size parameter of $B$. braunii cells in colonies over the PAR region is larger than 20 , which is greater than that of the particles used in previous studies. Then, applying the T-matrix or GMM method to such colonies is prohibitively time consuming and computationally intensive. Thus, a different approach is necessary to predict the absorption cross-section of $B$. braunii colonies.

The present study reports experimental measurements of the spectral average mass absorption cross-section of $B$. braunii in the PAR region, growing either as free-floating single cells or as colonies. To interpret the experimental results, a Monte Carlo ray tracing algorithm was developed and used to assess the effects of pigment concentrations, colony spatial configuration, and colony extracellular matrix on the spectral average mass absorption cross-section of $B$. braunii cells.

\section{Experiments}

\subsection{Species and cultivation}

The B. braunii race B strain 761 was obtained from Algobank (Caen, France) [29]. The B. braunii microalgae were cultivated in a flat panel airlift photobioreactor with a working volume of $270 \mathrm{~mL}$, thickness of $2 \mathrm{~cm}$, and illuminated surface area of $135 \mathrm{~cm}^{2}$. The PBR was designed to reduce the hydrodynamic stresses on the cells during cultivation [12]. A photon flux density of $300 \mu \mathrm{mol}_{\mathrm{h} \nu} / \mathrm{m}^{2} \mathrm{~s}$ from warm white LEDs was delivered normally incident onto the PBR surface. Fresh medium was fed continuously into the PBR to maintain constant nutrient levels under chemostat operation [7]. Culture A was nutrient-replete and consisted mostly of free-floating cells (Fig. 1a). By contrast, Culture B was nitrogen-limited and contained mostly colonies (Fig. 1b). This can be explained by changes in EPS production, which is a main driver of colony formation and has been shown to increase in $B$. braunii under nitrogen starvation $[6,30,31]$. Culture A was cultivated in modified Chu 13 medium with the following composition (in $\mathrm{g} / \mathrm{L}$ ): $\mathrm{KNO}_{3}(0.2)$, $\mathrm{K}_{2} \mathrm{HPO}_{4}(0.04), \mathrm{MgSO}_{4} \cdot 7 \mathrm{H}_{2} \mathrm{O}(0.1), \mathrm{CaCl}_{2} \cdot 6 \mathrm{H}_{2} \mathrm{O}(0.08)$, Fe citrate (0.01), citric acid (0.1); micro elements: $\mathrm{B}, \mathrm{Mn}$ (both at $0.5 \mathrm{ppm}$ ), $\mathrm{Zn}$ (0.05 ppm), Cu, Co, Mo (0.02 ppm). The medium was sterilized by autoclaving at $121{ }^{\circ} \mathrm{C}$ for $25 \mathrm{~min}$. Nutrient limitation in Culture B was achieved by cultivation in Chu13 medium without $\mathrm{KNO}_{3}$ [32]. For both Cultures A and B, the PBR dilution rate was set to $0.0151 / \mathrm{h}$. The culture medium $\mathrm{pH}$ was continuously monitored using a $\mathrm{pH}$ sensor (Mettler Toledo SG 3253) and was maintained at 7.5 by automatic injection of gaseous $\mathrm{CO}_{2}$ via the pH-transmitter (Mettler Toledo M300). 


\subsection{Biomass concentration}

The dry biomass concentration $X$ (in $\mathrm{kg} / \mathrm{m}^{3}$ ) was measured by filtering $5 \mathrm{~mL}$ of culture through a pre-dried and pre-weighed $0.45 \mu \mathrm{m}$ pore size cellulose filter. The filters were dried for a minimum of $24 \mathrm{~h}$ in an oven at $105{ }^{\circ} \mathrm{C}$ and weighed after being cooled in a desiccator for $30 \mathrm{~min}$. Each sample was analyzed in triplicates and the mean value of the dry biomass concentration was reported.

\subsection{Pigment concentrations}

Photosynthetic pigments chlorophyll $a$ and $b$ and photoprotective carotenoids were extracted in pure methanol and quantified spectrophotometrically. First, a volume of $0.5 \mathrm{~mL}$ of the continuous airlift PBR culture at steady state was centrifuged at $13,400 \mathrm{rpm}(12,100 \mathrm{~g})$ for $10 \mathrm{~min}$. The medium was then discarded and the cells were resuspended in $1.5 \mathrm{~mL}$ of pure methanol and sonicated for $20 \mathrm{~s}$. The samples were placed in an oven at $45{ }^{\circ} \mathrm{C}$ for $1 \mathrm{~h}$. The extract was then centrifuged again. Measurements of the spectral optical density $O D_{\lambda}$ of the supernatant were taken at wavelengths $750,665,652$, and $480 \mathrm{~nm}$ using a UV-vis spectrophotometer (Jasco V-730 Easton, MD). Here also, all extractions were performed in triplicates. Chlorophyll $a$ and $b$ concentrations, denoted by $C_{C h l a}$ and $C_{C h l b}$, were estimated according to [33]

$C_{C h l a}[\mathrm{mg} / \mathrm{L}]=-8.0962\left(O D_{652}-O D_{750}\right)+16.5169\left(O D_{665}-O D_{750}\right)$

$C_{C h l b}[\mathrm{mg} / \mathrm{L}]=27.4405\left(O D_{652}-O D_{750}\right)-12.1688\left(O D_{665}-O D_{750}\right)$.

Finally, B. braunii has no photosynthetic carotenoids [34,35]. Thus, the concentration of photoprotective carotenoids $C_{P P C}$ was estimated according to [36]

$C_{P P C}[\mathrm{mg} / \mathrm{L}]=4\left(O D_{480}-O D_{750}\right)$.

\subsection{Size distribution}

A cell count of Culture A was conducted using a $200 \mu \mathrm{m}$ deep Malassez cell. The major $a$ and minor $b$ Ferret diameters of individual cells were measured using a Zeiss microscope and ImageJ software for the single cell Culture A. Then, the cell aspect ratio $\varepsilon$ was calculated as $\varepsilon=a / b$. The radius of a surface-area equivalent sphere $r_{c, e q}$ was calculated as [37]

$r_{c, e q}=\frac{1}{4}\left(2 a^{2}+2 a b \frac{\sin ^{-1} e}{e}\right)^{1 / 2}$ where $e=\frac{\left(\varepsilon^{2}-1\right)^{1 / 2}}{\varepsilon}$.

The frequency distribution $f\left(r_{c, e q, i}\right)$ of a given equivalent radius $r_{c, e q, i}$ was estimated according to [38]

$f\left(r_{c, e q, i}\right)=\frac{N\left(r_{c, e q, i}\right)}{N_{T}}=\frac{N\left(r_{c, e q, i}\right)}{\sum_{i=1}^{M} N\left(r_{c, e q, i}\right)}$.

Here, $N\left(r_{c, e q, i}\right)$ is the number of cells per unit volume of culture with equivalent radius between $r_{c, e q, i}$ and $r_{c, e q, i}+\Delta r_{c, e q}$, and $N_{T}$ is the total number density of cells per unit volume of culture (in cells $/ \mathrm{m}^{3}$ ). A minimum of 450 cells were counted for single cell Culture A, with a bin size $\Delta r_{c, e q}$ of $0.05 \mu \mathrm{m}$ and $M=78$ bins.

For Culture B, the number of cells per colony $N_{c}$ was estimated manually. A total of 207 colonies containing more than 4000 cells were characterized. Due to the difficulty associated with counting cells in three-dimensional colonies from two-dimensional images the results are not considered a rigorous characterization of the colony size distribution. Instead, the count was performed to give a qualitative understanding of the range of colony sizes present in Culture $B$. Approximately $35 \%$ of the characterized cells were free-floating cells while $65 \%$ were in colonies of 2 or more cells. The vast majority of colonies had a number of cells $N_{c}<100$. Yet, colonies with a number of cells $N_{c}$ larger than 200 were observed.

\subsection{Microalgae radiation characteristics}

The procedure for measuring the radiation characteristics of microalgae has been described in previous references [39-41], and need not be repeated here. In brief, the normal-normal transmittance $T_{n n, \lambda}$ and normal-hemispherical transmittance $T_{n h, \lambda}$ of a $10 \mathrm{~mm}$ pathlength quartz cuvette containing a dilute suspension of microalgae in phosphate buffer saline (PBS) were measured at wavelengths $\lambda$ between 400 and $750 \mathrm{~nm}$ in $1 \mathrm{~nm}$ increments using a UV-vis-NIR spectrophotometer (Agilent Cary 5000, Santa Clara, CA) and an integrating sphere attachment (Agilent Cary DRA-2500, Santa Clara, CA). The scattering phase function $\Phi_{\lambda}(\Theta)$ for single cell B. braunii reported in Ref. [41] was used to estimate the correction factor $\varepsilon_{n}$ for Culture A using a detector with half acceptance angle of $\Theta_{a}=3^{\circ}$ such that $\varepsilon_{n}^{A}=0.37$. The correction factor for Culture $\mathrm{B}$ was taken as $\varepsilon_{n}^{B}=0.63$. It was estimated using a volume and average projected area equivalent coated sphere approximation demonstrated by Kandilian et al. [24] and the complex refractive index data for $B$. braunii reported in Ref. [42]. The values of $\varepsilon_{n}^{A}$ and $\varepsilon_{n}^{B}$ for each culture were assumed to be constant over the PAR region $[43,44]$. The spectral absorption $\kappa_{\lambda}$ and scattering $\sigma_{s, \lambda}$ coefficients were calculated for different biomass concentrations to ensure that single scattering through the dilute suspension prevailed [41]. Then, the spectral average mass absorption $\bar{A}_{a b s, \lambda}$ and scattering $\bar{S}_{\text {sca }, \lambda}$ cross-sections (in $\mathrm{m}^{2} / \mathrm{kg}$ ) were estimated according to [39]

$\bar{A}_{a b s, \lambda}=\kappa_{\lambda} / X$ and $\bar{S}_{s c a, \lambda}=\sigma_{s, \lambda} / X$

where $X$ is the dry biomass concentration in each culture (in $\mathrm{kg} / \mathrm{m}^{3}$ ).

\section{Modeling}

\subsection{Problem statement}

Let us consider a spherical cell of $B$. braunii with radius $r_{c, e q}$ and spectral effective complex index of refraction $m_{c, \lambda}$. The cell can be approximated as optically homogeneous, as demonstrated by Bhowmik et al. [45]. The cell is surrounded by a non-absorbing PBS solution whose spectral refractive index is given by the Cauchy dispersion relation [46]

$n_{m, \lambda}=A+\frac{B}{\lambda^{2}}+\frac{C}{\lambda^{4}}$.

Here, the wavelength $\lambda$ is expressed in $\mu \mathrm{m}$ and the coefficients for PBS are $A=1.32711, B=2.6 \times 10^{-3} \mu \mathrm{m}^{2}$, and $C=5 \times 10^{-5} \mu \mathrm{m}^{4}$ [47].

In addition to simulating light absorption by a single $B$. braunii cell, colonies were simulated as either fractal aggregates of monodisperse cells embedded (or not) in a spherical ECM or as ordered monodisperse cells at the periphery of a hollow spherical colony embedded (or not) in a spherical ECM. The former configuration was chosen to approximately represent the colonies observed in Fig. 1b. The latter configuration was chosen to approximately represent the quasi-spherical hollow colony configuration observed by Weiss et al. [14] for a different strain of $B$. braunii. Fig. 2 illustrates the four different colony configurations simulated. Each colony was exposed to collimated visible photons of wavelength $\lambda$. The latter was considered to be much smaller than the cell radius $r_{c, e q}$ such that the cell size parameter $x_{c}=2 \pi r_{c, e q} / \lambda \gg 1$ and geometric optics prevailed. Then, photons were (a) reflected or refracted at the cell/medium interface, at the medium/ ECM interface, and at the ECM/cell interface, (b) transmitted through the cell(s) and/or ECM, or (c) absorbed within the cell volume.

\subsection{Optical properties}

First, the spectral complex index of refraction $m_{c, \lambda}^{A}=n_{c, \lambda}^{A}+i k_{c, \lambda}^{A}$ of $B$. 
(a)

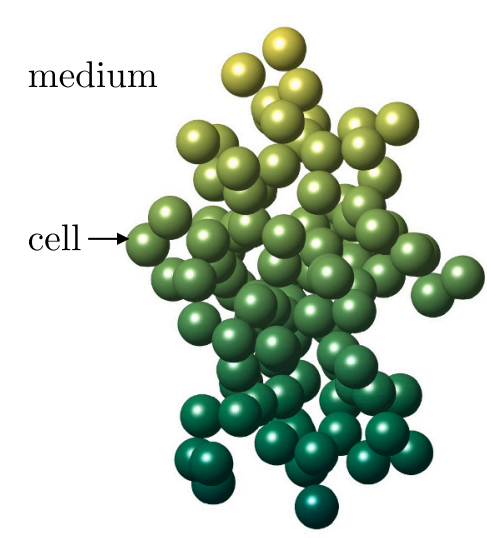

(c)

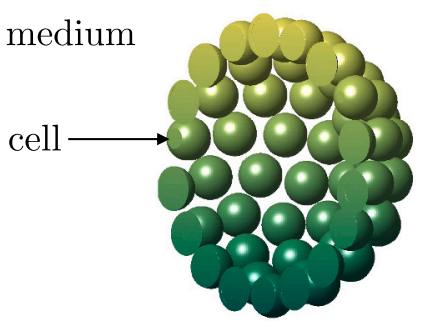

(b)

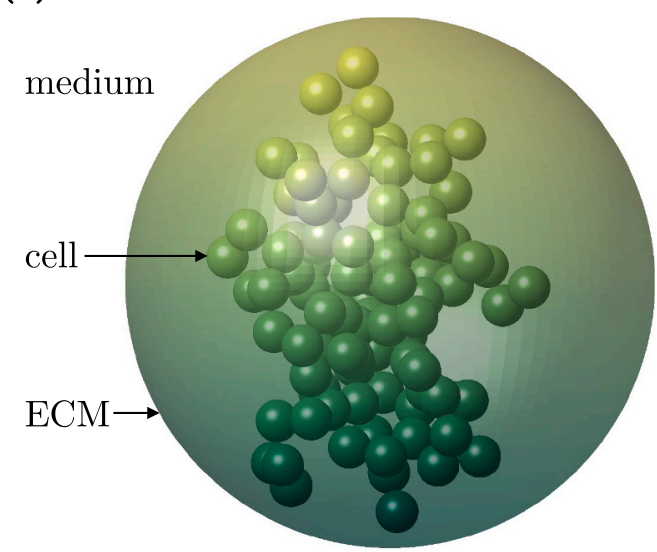

(d)

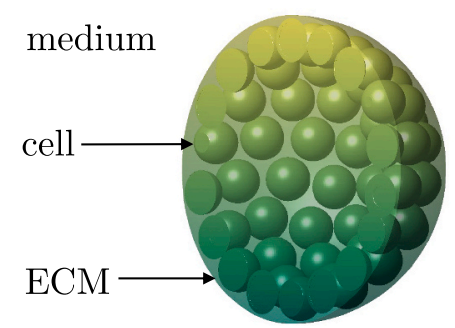

Fig. 2. Simulated configurations of $B$. braunii colonies as (a) a fractal colony of $N_{c}=100$ cells with radius $r_{c, e q}$, refractive index $m_{c, \lambda}$ in surroundings with refractive index $n_{m, \lambda}$, (b) a fractal colony of $N_{c}$ $=100$ cells in a non-absorbing, spherical extracellular matrix (ECM) of radius $r_{E C M}$ and refractive index $n_{E C M}$, section view of (c) a spherical colony of $N_{c}=100$ cells, and (d) a spherical colony of $N_{c}=$ 100 cells in a spherical ECM illustrating the hollow spherical shape. braunii cells in Culture A was determined experimentally. To do so, the cell size distribution as well as the spectral average absorption $\bar{C}_{a b s, \lambda}$ and scattering $\bar{C}_{s c a, \lambda}$ cross-sections of Culture A over the PAR region were obtained experimentally. This information was used to retrieve the cell spectral refractive $n_{c, \lambda}^{A}$ and absorption $k_{c, \lambda}^{A}$ indices via an inverse method developed in Ref. [42] based on Lorenz-Mie theory and assuming that the scatterers were spherical and polydisperse [48].

For Culture $\mathrm{B}$, the refractive index $n_{c, \lambda}^{B}$ of the cells in the colonies was assumed to be identical to that of the single cells in Culture A, i.e., $n_{c, \lambda}^{A}=n_{c, \lambda}^{B}$. On the other hand, a general expression for the cell absorption index $k_{c, \lambda}$ can be written as [20]

$k_{c, \lambda}=\frac{\lambda}{4 \pi} \sum_{j} C_{j} E a_{\lambda, j}$.

Here, $C_{j}$ (in $\mathrm{kg} / \mathrm{m}^{3}$ ) is the concentration of pigment " $\mathrm{j}$ " in the cell and $E a_{\lambda, j}\left(\right.$ in $\mathrm{m}^{2} / \mathrm{kg}$ ) is the spectral mass absorption cross-section of pigment "j". The pigment mass fraction can be defined as $x_{j}=C_{j} / C_{p i g}$ where $C_{p i g}$ is the total pigment concentration in the cell (in $\mathrm{kg} / \mathrm{m}^{3}$ ) i.e., $C_{p i g}=\sum_{j} C_{j}$.

Then, Eq. (7) can be written as

$k_{c, \lambda}=\frac{\lambda}{4 \pi} C_{p i g} \sum_{j} x_{j} E a_{\lambda, j}=\frac{\lambda}{4 \pi} C_{p i g} E a_{\lambda, e f f}$

where $E a_{\lambda, \text { eff }}$ (in $\mathrm{m}^{2} / \mathrm{kg}$ ) is the effective mass absorption cross-section for a $\mathrm{kg}$ of pigment with a given combination of pigment mass fractions $x_{j}$.

Assuming that the pigment mass fractions $x_{\text {Chla }}, x_{C h l b}$, and $x_{P P C}$ in Cultures $\mathrm{A}$ and $\mathrm{B}$ are identical, then $E a_{\lambda, \text { eff }}$ can be retrieved from $k_{c, \lambda}^{A}$. This assumption was verified in Cultures $\mathrm{A}$ and $\mathrm{B}$, as discussed later. Then, assuming equal dry biomass densities and cell water fractions between Cultures A and B the absorption index $k_{c, \lambda}^{B}$ of the cells in the colonies of Culture B can be estimated using $k_{c, \lambda}^{A}$ and the total pigment concentrations in Cultures A and B such that [38]

$k_{c, \lambda}^{B}=\frac{C_{p i g}^{B}}{C_{p i g}^{A}} k_{c, \lambda}^{A}=\frac{x_{p i g}^{B}}{x_{p i g}^{A}} k_{c, \lambda}^{A}$

where $x_{\text {pig }}^{A}$ and $x_{\text {pig }}^{B}$ are the pigment mass fractions of Cultures A and B, respectively. Note that in the case of dissimilar pigment mass fractions between the two cultures, Eq. (7) can be used to estimate the cell absorption index $k_{c, \lambda}$ based on the pigment spectral mass absorption crosssection $E a_{\lambda, j}$ reported in the literature [49].

\subsection{Computational colony generation}

As previously discussed, the $B$. braunii colonies were modeled as either fractal aggregates (Figs. 2a and $2 \mathrm{~b}$ ) or ordered spherical colonies where the cells were arranged on the surface of a sphere (Figs. $2 \mathrm{c}$ and 2d). These two configurations were chosen to approximately represent the colony structures observed in Fig. 1b and in Ref. [14], respectively. All computationally generated colonies were comprised of monodisperse spheres of radius $\bar{r}_{c, e q}=3.71 \mu \mathrm{m}$ corresponding to the equivalent average radius of the cells in polydisperse Culture A.

Fractal colonies of $N_{c}$ monodisperse cells of radius $\bar{r}_{c, e q}$ satisfied the expression [23]

$N_{c}=k_{f}\left(\frac{R_{g}}{\bar{r}_{c, e q}}\right)^{D f}$

where $R_{g}$ is the radius of gyration defined as the mean-squared of the distances between the aggregate center of mass and the centers of the cells, $D_{f}$ is the fractal dimension, and $k_{f}$ is the fractal prefactor. Here, the fractal dimension was prescribed as $D_{f}=2.3$ corresponding to phytoplankton [50]. The prescribed fractal prefactor was $k_{f}=1.6$. Colonies were generated using a ballistic fractal aggregate technique [51]. To generate aggregates, cells were added to the simulation domain one at a time and set on a random walk. The domain initially contained two touching cells. The marching cell stopped when the distance between the closest cell in the aggregate and the new cell was less than the maximum allowed distance imposed as $1 \%$ of the cell radius i.e., $4 \mathrm{~nm}$. No cell overlap was permitted. If the radius of gyration $R_{g}$ of the new aggregate satisfied Eq. (10) to within $\pm 1 \%$ using the prescribed values of $D_{f}$ and $k_{f}$, the cell was permitted to stay in the aggregate. Otherwise it was removed. This process was repeated until the desired number of cells $N_{c}$ was attained. This technique yielded aggregates with average fractal dimension $D_{f}$ and prefactor $k_{f}$ within $\pm 1 \%$ of their prescribed 
values.

Ordered spherical colonies were generated using an algorithm that uniformly distributes a given number of points on the surface of a sphere [52]. These points were taken as the geometric center of monodisperse spherical cells of radius $\bar{r}_{c, e q}$ in the colonies. The minimum allowed distance between the center of two adjacent cells was $2 \bar{r}_{c, e q}$ corresponding to point contact.

Finally, to assess the effects of ECM on light absorption by colonies, the previously generated fractal or ordered spherical colonies were placed at the center of a spherical non-absorbing ECM of refractive index $n_{E C M}=1.48$ [53]. Absorption by the colony ECM was assumed to be negligible compared to that by the strongly absorbing pigmented cells over the PAR region and based on the transparent appearance of the ECM in Fig. 1b. The center of the ECM was located at the center of mass of the cell ensemble. The ECM thickness was defined as the minimum distance between the cell/ECM interface and the ECM/ medium interface and taken as one tenth of the cell radius, i.e., $t_{E C M}=r_{c, e q} / 10=371 \mathrm{~nm}$. This morphological model can lead to areas where ECM in fractal colonies is unrealistically thick (see Fig. 2b). However, this simplification was used to determine if the effect of ECM on the mass absorption cross-section $\bar{A}_{a b s, \lambda}^{c o}$ of cells in a colony was significant enough to warrant a more refined geometric representation of a colony in its ECM.

\subsection{Monte Carlo ray tracing method}

In order to predict the spectral average mass absorption cross-section $\bar{A}_{a b s, \lambda}$ of $B$. braunii cells in the form of a single cell or a colony, a Monte Carlo ray tracing (MCRT) method similar to that used by Zhu et al. [54,55] was employed. A large number of discrete collimated photon bundles or "rays" emanating from randomized locations on a square plane of area $A_{d}$ were launched at the different colony configurations under investigation. At each interface, the probability of reflection or refraction was determined by Fresnel's equations and the eventual outcome was decided by a random number between 0 and 1 selected from a uniform distribution. The new ray direction was governed by specular reflection for reflected rays and Snell's law for refracted rays [56]. The location of the next interface the ray encountered was calculated from the new ray direction and the geometry of the cell or colony. Throughout the lifespan of the ray, its total pathlength through the single cell or the cells in the colony was recorded. This process continued until the ray was either reflected away from or transmitted through the cell or colony. Then, the transmissivity associated with its pathlength, $\tau_{\lambda}\left(l_{p}\right)$ was calculated using Beer-Lambert's law given by [56]

$\tau_{\lambda}\left(l_{p}\right)=e^{-\kappa_{c, \lambda} l_{p}}$.

Here, the cell absorption coefficient $\kappa_{c, \lambda}$ (in $\mathrm{m}^{-1}$ ) was expressed as $\kappa_{c, \lambda}=4 \pi k_{c, \lambda} / \lambda$ where $k_{c, \lambda}$ is the cell absorption index retrieved from experimental data using the inverse method previously discussed [42] or predicted by Eq. (9) [56]. A random number between 0 and 1 was then chosen from the uniform distribution and compared with the value of $\tau_{\lambda}$. If the random number was greater than $\tau_{\lambda}$, the ray was counted towards the total number of rays absorbed $N_{a b s, \lambda}$. Otherwise the ray was considered transmitted or reflected and was counted towards the total number of rays scattered by the cell or colony $N_{s c a, \lambda}$. Once the fate of all rays was determined, the spectral absorption efficiency factor of the single cell (superscript "sc") or colony (superscript "co") was calculated as the ratio of the number of rays absorbed $N_{a b s, \lambda}$ to the total number of rays attenuated $N_{e x t, \lambda}=N_{s c a, \lambda}+N_{a b s, \lambda}$, i.e.,

$Q_{a b s, \lambda}=\frac{N_{a b s, \lambda}}{N_{e x t, \lambda}}$.

For each type of colony comprised of $N_{c}$ cells, $N_{c o}=100$ different colonies were generated. The number of cells present in the colony $N_{c}$ ranged from 10 to 900 cells. Then, for each one of these colonies, the computation of $Q_{a b s, \lambda}$ was repeated for $N_{o}=10$ different colony orientations with respect to the incident collimated photons. For a given colony and colony orientation, $10^{4}$ rays were simulated to predict the value of $Q_{a b s, \lambda}$. Then, the $N_{c o} \times N_{o}$ values of $Q_{a b s, \lambda}$ were averaged to obtain the orientation-averaged absorption efficiency factor. Note that increasing by one order of magnitude the number of rays simulated resulted in a change of less than $0.1 \%$ in $Q_{a b s, \lambda}$ for any value of $N_{c}$ at $680 \mathrm{~nm}$ which approximately corresponds to one of the absorption peaks of chlorophyll $a$. Thus, simulating $10^{4}$ rays was deemed sufficient to achieve numerical convergence (see Supplementary Material). Spectral simulations were performed in $10 \mathrm{~nm}$ increments between 400 and $750 \mathrm{~nm}$.

Furthermore, the results from the Monte Carlo ray tracing simulations were not extended to the scattering efficiency factor $Q_{s c a, \lambda}=N_{s c a, \lambda} / N_{\text {ext }, \lambda}$. Indeed, the MCRT method ignored diffraction and interference effects and could not capture the associated enhancement or suppression of the scattering field. Thus, the total number of rays attenuated $N_{\text {ext }, \lambda}$ was always equal to the total number of incident rays so that the value of the extinction efficiency factor $Q_{\text {ext }, \lambda}$ was always equal to unity, i.e., $Q_{\text {ext }, \lambda}=1=Q_{a b s, \lambda}+Q_{s c a, \lambda}$. The MCRT method is valid in the limiting case of the geometric optics approximation i.e., when $x_{c} \gg 1$ and $\left|m_{\lambda}-1\right| x_{c} \gg 1$, where $x_{c}=2 \pi r_{c, e q} / \lambda$ is the cell size parameter and $m_{\lambda}=n_{\lambda}+i k_{\lambda}$ is the relative complex index of refraction $m_{\lambda}=m_{c, \lambda} / n_{m, \lambda}$. However, due to the optically soft nature of microalgae cells, the condition $\left|m_{\lambda}-1\right| x_{c} \gg 1$ was not satisfied in the PAR region. Nonetheless, the MCRT method remains capable of predicting the absorption efficiency factor of microalgae cells and colonies, as demonstrated later for both single cells and aggregates of cells.

The spectral absorption cross-section of a single spherical cell $C_{a b s, \lambda}^{s c}$ (in $\mathrm{m}^{2}$ ) is a function of (i) the cell size parameter $x_{c}$, (ii) the cell relative complex index of refraction $m_{\lambda}$, and (iii) the cell equivalent radius $r_{c, e q}$ and can be expressed as [48]

$C_{a b s, \lambda}^{s c}\left(x_{c}, m_{\lambda}\right)=Q_{a b s, \lambda}^{s c}\left(x_{c}, m_{\lambda}\right) \pi r_{c, e q}^{2}$.

For a suspension of polydisperse single cells, the average absorption cross-section $\bar{C}_{a b s, \lambda}^{s c}$ can be expressed as a weighted sum of the absorption cross-sections of all simulated cells according to

$\bar{C}_{a b s, \lambda}^{s c}=\int_{0}^{\infty} C_{a b s, \lambda}^{s c}\left(x_{c}, m_{\lambda}\right) f\left(x_{c}\right) \mathrm{d} x_{c}$

where $f\left(x_{c}\right)$ is the fraction of cells having size parameter between $x_{c}$ and $x_{c}+\mathrm{d} x_{c}$. For Culture A, the average absorption cross-section can be estimated according to

$\bar{C}_{a b s, \lambda}^{s c}=\sum_{i=1}^{M} C_{a b s, \lambda}^{s c}\left(x_{c, i}, m_{\lambda}\right) f\left(r_{c, e q, i}\right)$.

Similarly, the spectral orientation-averaged absorption cross-section $\bar{C}_{a b s, \lambda}^{c o}$ (in $\mathrm{m}^{2}$ ) of colonies with a given number of cells $N_{c}$ can be expressed as

$\bar{C}_{a b s, \lambda}^{c o}=\frac{1}{N_{c o} N_{o}} \sum_{k=1}^{N_{c o}} \sum_{j=1}^{N_{o}} Q_{a b s, \lambda, j, k}^{c o} A_{p, j, k}^{c o}$.

Here, $Q_{a b s, \lambda, j, k}^{c o}$ and $A_{p, j, k}^{c o}$ are the absorption efficiency factor and projected area of colony " $k$ " with orientation " $\mathrm{j}$ " (in $\mathrm{m}^{2}$ ). As described previously, $N_{c o}=100$ different colonies were generated and $N_{o}=10$ random orientations were simulation for each colony. The orientationaveraged absorption cross-section $\bar{C}_{a b s, \lambda}^{c o}$ not only depends on the cell size parameter $x_{c}$ and relative complex index of refraction $m_{\lambda}$ but also the number of cells and their arrangement as well as the presence, size, and optical properties of the ECM. For colonies with spherical ECM, the projected area $A_{p, j, k}^{c o}$ was readily calculated from the colony ECM radius $r_{E C M, k}$, i.e., $A_{p, j, k}^{c o}=\pi r_{E C M, k}^{2}$. Otherwise, the colony projected area for colony " $\mathrm{k}$ " and orientation " $\mathrm{j}$ " was estimated from the surface area $A_{d}$ of the plane from which the collimated incident photons emanated, the 
number of photons absorbed or scattered $N_{e x t, j, k}=N_{a b s, j, k}+N_{s c a, j, k}$, and the total number of collimated photons $N_{\text {total }}$, i.e.,

$A_{p, j, k}^{c o}=\frac{N_{\text {ext }, j, k}}{N_{\text {total }}} A_{d}$

Finally, to enable comparison between experimental measurements and numerical simulations for both single cells and colonies, the average absorption cross-section on a unit mass basis $\bar{A}_{a b s, \lambda}^{s c}\left(\right.$ in $^{2} / \mathrm{kg}$ ) of single cells can be estimated from the predicted average absorption cross-section $\bar{C}_{a b s, \lambda}^{s c}$ according to [42]

$\bar{A}_{a b s, \lambda}^{s c}=\bar{C}_{a b s, \lambda}^{s c} \frac{N_{T}}{X}$

where $N_{T}$ is the cell density (in cells $/ \mathrm{m}^{3}$ ) of Culture A and $X$ is the corresponding dry biomass concentration (in $\mathrm{kg} / \mathrm{m}^{3}$ ). Similarly, the predicted average mass absorption cross-section $\bar{A}_{a b s, \lambda}^{c o}$ (in $\mathrm{m}^{2} / \mathrm{kg}$ ) of cells in computationally generated colonies of $N_{c}$ monodisperse cells is given by

$\bar{A}_{a b s, \lambda}^{c o}=\bar{C}_{a b s, \lambda}^{c o} \frac{N_{T}}{X} \frac{1}{N_{c}}$.

\subsection{Validation}

In order to validate the Monte Carlo ray tracing algorithm and confirm that the geometric optics approximation can be used to predict the absorption cross-section of optically soft microalgae, we considered Chlamydomonas reinhardtii strain CC125 whose spectral complex index of refraction in the PAR region (400-750 nm) was retrieved by Lee et al. [42] from measurements of their absorption and scattering cross-sections and size distribution $f\left(r_{c, e q}\right)$. Note that for the reported values of cell equivalent radius $r_{c, e q}$ and complex index of refraction $m_{c, \lambda}$, the geometric optics requirement $\left|m_{\lambda}-1\right| x_{c} \gg 1$ was not satisfied. To validate the MCRT algorithm, the absorption cross-section $\bar{C}_{a b s, \lambda}$ of the polydisperse cells over the PAR region was calculated using both the Lorenz-Mie theory and the MCRT method. The cell size parameter $x$ ranged from 19 to 99 , while the relative refractive $m_{\lambda}$ and absorption index $k_{\lambda}$ ranged from 1.008 to 1.024 and $10^{-6}$ to 0.006 , respectively. Fig. 3a compares $\bar{C}_{a b s, \lambda}$ obtained from both methods as a function of wavelength $\lambda$. It indicates that excellent agreement was found between Lorenz-Mie theory and the MCRT method confirming that the geometric optics approximation is appropriate for predicting the spectral absorption cross-section of a single optically soft microalgae cell. However, as a result of neglecting diffraction effects, the predicted values of the spectral scattering cross-section $\bar{C}_{s c a, \lambda}$ from the MCRT method differed significantly from the values predicted using LorenzMie theory (not shown).

Furthermore, Fig. 3b compares the average absorption cross-section $\bar{C}_{a b s}^{c o}$ of aggregates of large monodisperse spheres as a function of the number of spheres $N_{c}$ predicted by the MCRT method and by the superposition T-matrix method reported in Ref. [24]. The superposition Tmatrix method numerically solves Maxwell's equations for aggregates by summing the contribution of each sphere to the electromagnetic field at any given location [57]. Unlike the MCRT method which accounts only for reflection and refraction, the superposition T-matrix method accounts for all phenomena contributing to scattering including reflection, refraction, diffraction, and interferences [57]. Aggregates with up to 25 large spheres of size parameter $x$ of 10 or 20 and complex index of refraction of $m=1.0165+i 0.003$ were simulated. The fractal prefactor and dimension was $k_{f}=1.6$ and $D_{f}=2.3$, respectively. Here also, excellent agreement was observed between the values of $\bar{C}_{a b s}^{c o}$ predicted by the T-matrix method and the MCRT method. This indicates that the MCRT method is capable of accurately predicting the absorption cross-section of aggregates of large and optically soft cells such as microalgae colonies. (a)

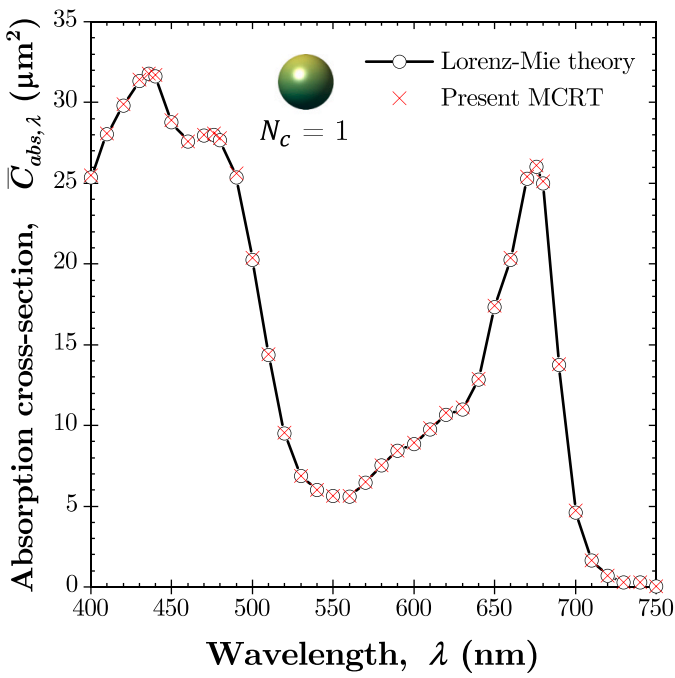

(b)

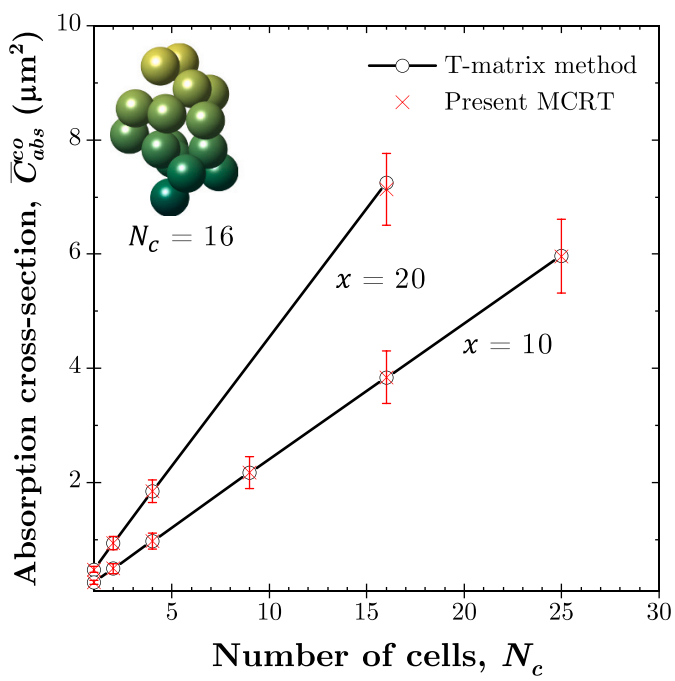

Fig. 3. (a) Spectral average absorption cross-section $\bar{C}_{a b s, \lambda}$ for Chlamydomonas reinhardtii strain $\mathrm{CC} 125$ over the photosynthetically active radiation (PAR) region using experimental size distribution and spectral optical properties reported in Ref. [42] and (b) average absorption cross-section $\bar{C}_{a b s}^{c o}$ of fractal aggregates $\left(k_{f}=1.6\right.$ and $D_{f}=2.3$ ) as a function of the number of spheres $N_{c}$ of size parameter $x$ of 10 and 20 predicted by the T-matrix method and obtained from Ref. [24] and the present Monte Carlo ray tracing (MCRT) algorithm. Error bars correspond to $95 \%$ confidence intervals.

\section{Results and discussion}

\subsection{Experiments}

Table 1 summarizes the growth conditions and the corresponding biomass concentration, pigment concentrations, and pigment mass fractions of both cultures considered. Culture A was grown under nutrient-replete conditions and contained free-floating single cells. Culture B was grown under nutrient-limited conditions and contained colonies. Under steady-state continuous operation, Cultures A and B achieved a dry biomass concentration $X$ of $1.78 \mathrm{~kg} / \mathrm{m}^{3}$ and $1.29 \mathrm{~kg} / \mathrm{m}^{3}$, respectively. Table 1 indicates that the pigment mass fractions $x_{\text {Chla, }}$, $x_{C h l \mathrm{~b}}$, and $x_{\mathrm{PPC}}$ remained nearly unchanged between Cultures A and $\mathrm{B}$. These results confirm the assumption of constant pigment mass fractions made in estimating the cell absorption index $k_{c, \lambda}^{B}$ using Eq. (8). Table 1 also indicates that total pigment concentration $C_{p i g}$ was lower in the nutrient-limited Culture B. Indeed, under nutrient-replete conditions, $B$. braunii tends to synthesize more photosynthetic pigments namely chlorophyll $a$ and $b[6,30]$. However, under the stress of 
Table 1

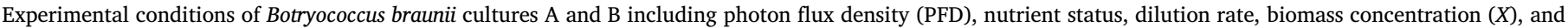
pigment mass fractions of chlorophyll $a, b$, photoprotective carotenoids, and total pigment mass fraction designated by $x_{\mathrm{Chl} a}, x_{\mathrm{Chl} b}, x_{P P C}$ and $x_{p i g}$, respectively.

\begin{tabular}{|c|c|c|c|c|c|c|c|c|c|}
\hline Culture & $\mathrm{PFD}\left(\mu \mathrm{mol} / \mathrm{m}^{2} \mathrm{~s}\right)$ & Nutrient status & Dilution rate $(1 / \mathrm{h})$ & $\mathbf{X}\left(\mathrm{kg} / \mathrm{m}^{3}\right)$ & $\mathbf{x}_{\mathrm{Chl} \boldsymbol{a}}(\mathrm{wt} \%)$ & $\mathbf{x}_{\text {Chlb }}(w t \%)$ & $\mathbf{x}_{\mathrm{PPC}}(\mathrm{wt} \%)$ & $\mathbf{x}_{\text {pig }}(w t$ \%) & Colonies \\
\hline A & 300 & Replete & 0.015 & 1.78 & 58.5 & 23.1 & 18.0 & 4.8 & No \\
\hline B & 300 & $\mathrm{~N}$ limited & 0.015 & 1.29 & 59.3 & 20.3 & 20.3 & 1.9 & Yes \\
\hline
\end{tabular}

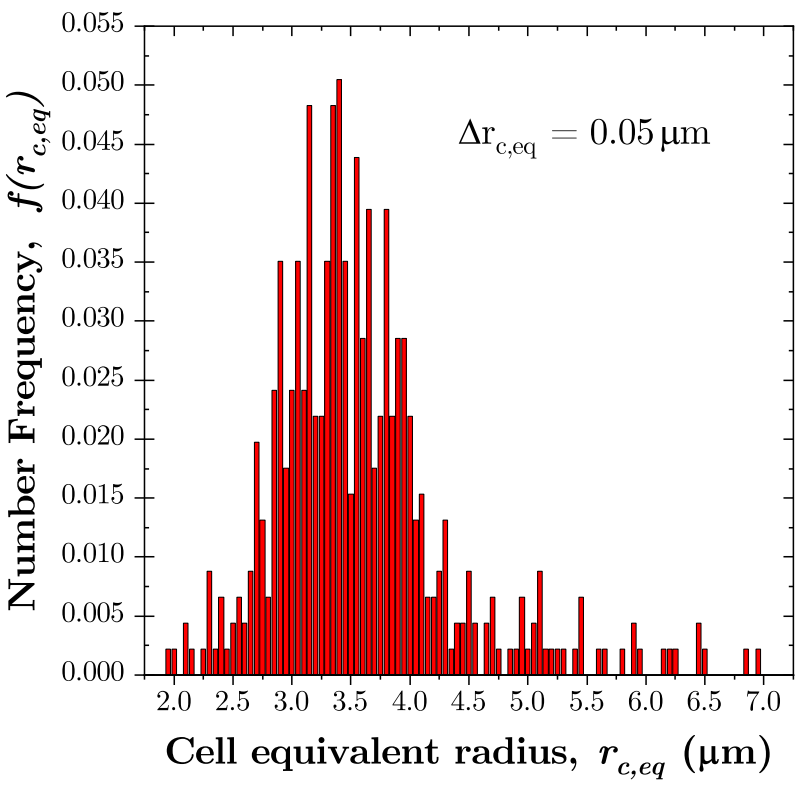

Fig. 4. Experimentally measured size distribution $f\left(r_{c, e q}\right)$ of single-cell Culture A.

nutrient-limited conditions less pigments are synthesized and more lipids and hydrocarbons are produced [6,30]. Fig. 4 shows the experimentally measured cell size distribution $f\left(r_{c, e q}\right)$ in Culture A. The average equivalent radius of cells was $\bar{r}_{c, e q}=3.71 \mu \mathrm{m}$.

Figs. $5 \mathrm{a}$ and $5 \mathrm{~b}$ show the spectral average mass absorption $\bar{A}_{a b s, \lambda}$ and scattering $\bar{S}_{\mathrm{sca}, \lambda}$ cross-sections measured over the PAR region, respectively for Culture A and B. For both cultures, the spectral average mass absorption cross-section $\bar{A}_{a b s, \lambda}$ exhibited several peaks including (i) at 437 and $678 \mathrm{~nm}$ corresponding to the absorption peaks of in vivo chlorophyll $a$ and (ii) at $475 \mathrm{~nm}$ and $653 \mathrm{~nm}$ corresponding to in vivo chlorophyll $b$ [49]. Moreover, $\bar{A}_{a b s, \lambda}$ decreased significantly across the PAR region for the colony containing Culture B compared to Culture A. This change could be attributed to (i) the lower pigment concentrations, (ii) the morphology of the colonies leading to shading effects and/or (iii) the presence of ECM. Unlike $\bar{A}_{a b s, \lambda}$, the spectral average mass scattering cross-section $\bar{S}_{s c a, \lambda}$ did not change significantly between Cultures A and B. Since $\bar{S}_{\text {sca }, \lambda}$ depends strongly on the cell refractive index, this observation supported the assumption that the cells in both cultures had the same refractive index, i.e., $n_{c, \lambda}^{A}=n_{c, \lambda}^{B}$. For both cultures, the spectral average mass scattering cross-section $\bar{S}_{\text {sca }, \lambda}$ exhibited several troughs at wavelengths corresponding to the absorption peaks observed in $\bar{A}_{a b s, \lambda}$. This phenomenon has also been observed in other microalgae species $[43,44,58]$.

Fig. 6a shows the refractive index $n_{c, \lambda}^{A}$ over the PAR region for cells in Culture A retrieved via the inverse method previously discussed [42]. Fig. 6a shows that cell refractive index varied only slightly over the PAR region. Additionally, Fig. 6a indicates that the refractive index retrieved for the current study was similar to that reported in Ref. [42] even though the two $B$. braunii strains were sourced from different suppliers, cultivated in different conditions, and had different cell sizes. Similarly, Fig. $6 \mathrm{~b}$ plots the absorption index $k_{c, \lambda}^{A}$ over the PAR region for cells in Culture A retrieved via the same inverse method [42]. Here, the cell (a)

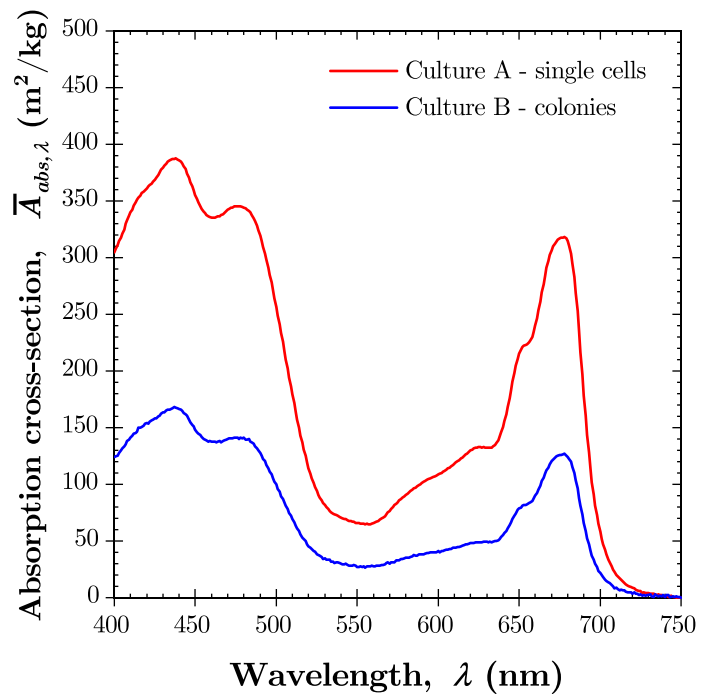

(b)

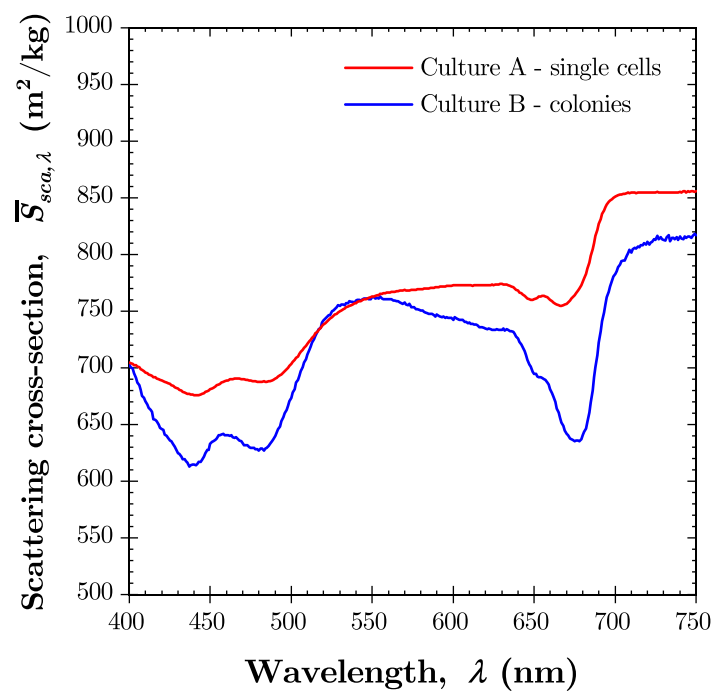

Fig. 5. Experimentally measured spectral average mass (a) absorption $\bar{A}_{a b s, \lambda}$ and (b) scattering $\bar{S}_{s c a, \lambda}$ cross-sections over the photosynthetically active radiation (PAR) region for Culture A featuring single cells and Culture B consisting of colonies of $B$. braunii race $\mathrm{B}$.

absorption index $k_{c, \lambda}^{A}$ exhibited peaks corresponding to the in vivo absorption peaks of chlorophyll $a$ and $b$, as observed in Fig. 5a. These values of $n_{c, \lambda}^{A}$ and $k_{c, \lambda}^{A}$ were used to estimate $n_{c, \lambda}^{B}$ and $k_{c, \lambda}^{B}$ necessary for the MCRT method to predict the spectral orientation-averaged mass absorption cross-section $\bar{A}_{a b s, \lambda}$ of the four colony configurations investigated.

\subsection{Simulations}

\subsubsection{Effect of colony morphology and ECM}

In order to assess the effect of colony morphology and of the presence of ECM on the mass absorption cross-section of $B$. braunii cells, the different colony configurations of Fig. 2 were simulated at wavelength $\lambda=680 \mathrm{~nm}$ with cell relative complex index of refraction 
(a)

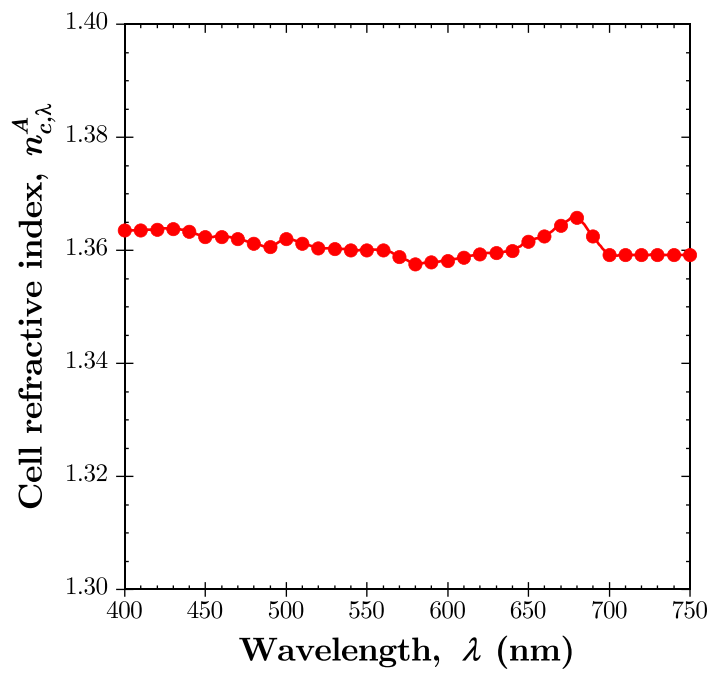

(b)

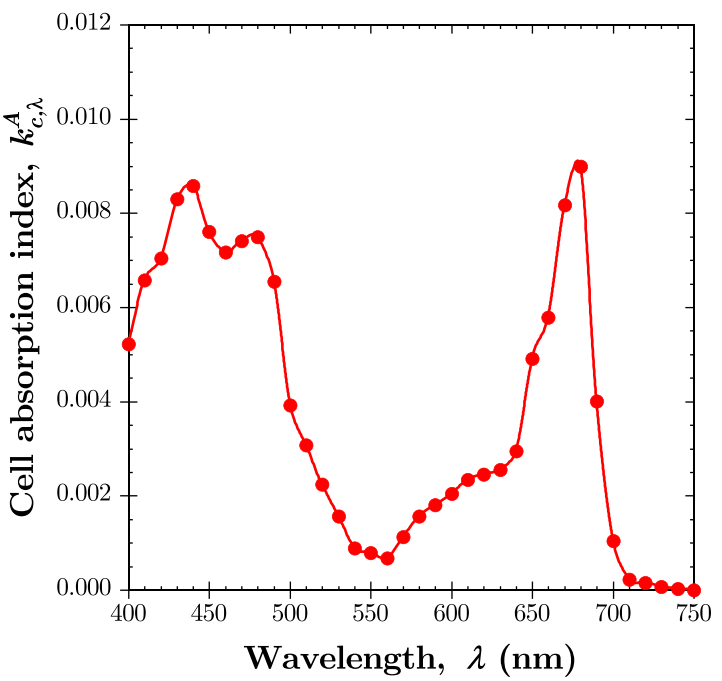

Fig. 6. Spectral (a) refractive $n_{c, \lambda}^{A}$ and (b) absorption $k_{c, \lambda}^{A}$ index for single cell $B$. braunii Culture A obtained from the measured average absorption $\bar{C}_{a b s, \lambda}$ and scattering $\bar{C}_{s c a, \lambda}$ cross-sections and an inverse method from Ref. [42].

$m_{c}^{B}=1.026+i 0.0035$ for a number of cells $N_{c}$ in the colony ranging from 10 to 900 . The wavelength of $680 \mathrm{~nm}$ was selected because it approximately corresponds to one of the absorption peaks of chlorophyll $a$ [49]. Fig. 7 plots the orientation-averaged absorption crosssection of colonies $\bar{C}_{a b s}^{c o}$ predicted by the MCRT method, normalized by the product of the absorption cross-section of a single cell of radius $\bar{r}_{c, e q}$ and the number of cells $N_{c}$ in the colony $\bar{C}_{a b s}^{c o}\left(N_{c}\right) / N_{c} C_{a b s}^{s c}$ as a function of $N_{c}$ for the four different colony configurations considered (see Fig. 2). Fig. 7 also plots the normalized absorption cross-section $\bar{C}_{a b s}^{c o}\left(N_{c}\right) / N_{c} C_{a b s}^{s c}$ of colonies simulated using Lorenz-Mie Theory based on the volume and average projected area equivalent coated sphere approximation suggested in Ref. [24]. The core and shell of the equivalent coated sphere had a complex index of refraction equal to that of the surrounding medium and of the cells, respectively. In addition, the outer shell radius $r_{o}$ and inner core radius $r_{i}$ for a given number of $N_{c}$ of cells in the colony were given by [24]

$r_{o}=\left(\frac{\bar{A}_{p}^{c o}\left(N_{c}\right)}{\pi}\right)^{1 / 2}$ and $r_{i}=\left(r_{o}^{3}-N_{c} \bar{r}_{c, e q}^{3}\right)^{1 / 3}$

where $\bar{A}_{p}^{c o}$ is the average projected area of the fractal aggregate with $N_{c}$ cells. The error bars correspond to two standard deviations or $95 \%$ confidence intervals among the $N_{o} \times N_{c o}$ colonies and orientations simulated. Fig. 7 indicates that the value of the normalized absorption

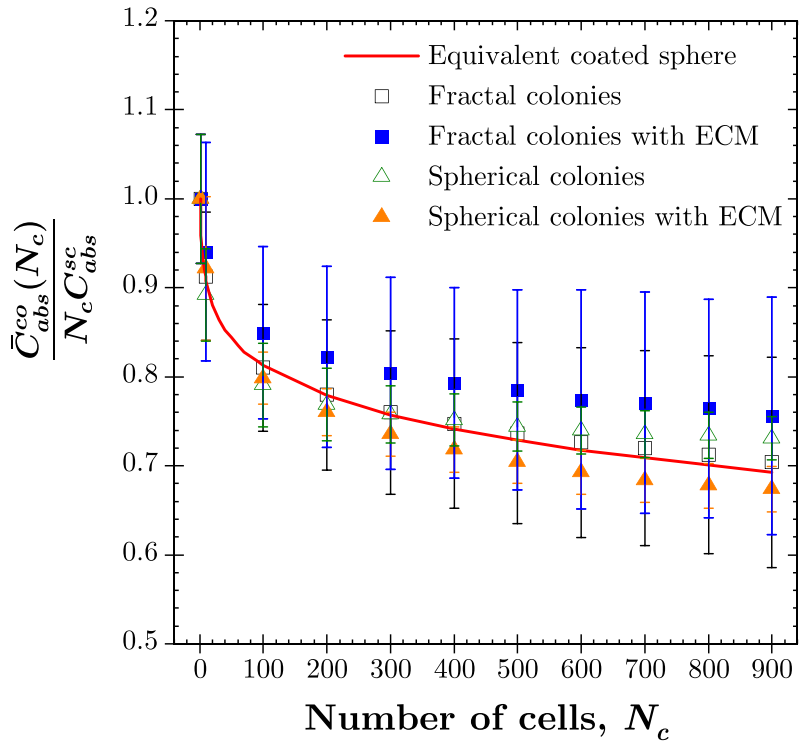

Fig. 7. Normalized orientation-averaged absorption cross-section of colonies $\bar{C}_{a b s}^{c o}\left(N_{c}\right) / N_{c} C_{a b s}^{s c}$ as a function of the number of cells in the colony $N_{c}$ for an equivalent coated sphere approximation and colonies consisting of fractal aggregates or ordered cells at the periphery of a sphere, with and without an extracellular matrix (ECM) (see Fig. 2). The equivalent coated sphere was simulated using Lorenz-Mie theory while the fractal and spherical colonies were simulated using the Monte Carlo ray tracing (MCRT) method. The cell complex index of refraction was $m_{c}^{B}=1.026+i 0.0035$. Error bars correspond to $95 \%$ confidence intervals.

cross-section varied less for spherical colonies as evidenced by the smaller error bars compared to those of fractal colonies. This was due to the fact that the structure of fractal colonies varies widely from one colony and/or orientation to another, unlike for spherical colonies.

Moreover, a ratio of $\bar{C}_{a b s}^{c o}\left(N_{c}\right) / N_{c} C_{a b s}^{s c}$ independent of $N_{c}$ and equal to unity would indicate that the absorption cross-section of a colony is equal to the sum of the contributions of each constitutive cell, i.e., the spatial arrangement of cells in colonies would not matter. However, Fig. 7 indicates that for all colony configurations considered, the ratio of $\bar{C}_{a b s}^{c o}\left(N_{c}\right) / N_{c} C_{a b s}^{s c}$ was less than 1.0 and decreased monotonically as the number of cells $N_{c}$ in the colonies increased. This was due to the shading effects among the cells as their number $N_{c}$ in the colony grew. Good agreement was found between the volume and average projected area equivalent coated sphere approximation and the normalized absorption cross-sections of fractal colonies predicted by the MCRT. However, assuming $\bar{C}_{a b s}^{c o}\left(N_{c}\right)=N_{c} C_{a b s}^{s c}$ would overestimate $\bar{C}_{a b s}^{c o}\left(N_{c}\right)$ as it neglects shading effects which can be significant for large values of $N_{c}$ and increasing values of $k_{c, \lambda}$. In practice however, the absorption crosssection of colonies with less than 10 cells can be approximated as $\bar{C}_{a b s}^{c o}\left(N_{c}\right) \simeq N_{c} C_{a b s}^{s c}$ within $\sim 10 \%$ error for the absorption index used here.

Furthermore, Fig. 7 suggests that the effect of ECM on the colonies' absorption cross-section was twofold. In the presence of ECM, photons were (i) reflected at the ECM/cell interface and (ii) internally reflected at the ECM/surrounding medium interface due to the index mismatch between ECM $\left(n_{E C M}=1.48\right)$ and the cells $\left(n_{c}=1.366\right)$ as well as between ECM and the surrounding medium $\left(n_{m}=1.333\right)$. Internal reflection at the ECM/medium interface caused photons to be reflected back into the ECM thus increasing the probability that they are eventually absorbed by the cells. This was particularly true in fractal colonies where the spherical ECM geometry exaggerated the increase in projected area (see Fig. 2b). This caused more photons to be internally reflected at the ECM/medium interface and slightly increased the absorption cross-section of cells. Unlike fractal colonies, the presence of ECM did not significantly increase the projected area of spherical 


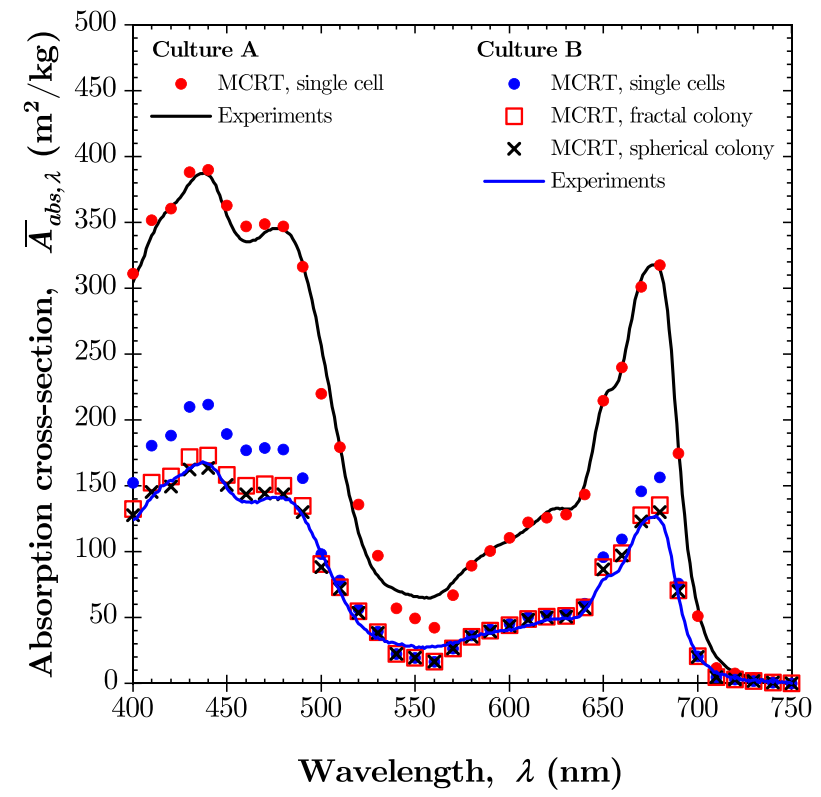

Fig. 8. Experimental measurement and Monte Carlo ray tracing (MCRT) predictions of the spectral average mass absorption cross-section $\bar{A}_{a b s, \lambda}$ over the photosynthetically active radiation (PAR) region for cells in Cultures A and B. The simulation results were plotted for (i) single cells using pigment concentrations measured from Culture A and Culture B, (ii) fractal colonies without extracellular matrix (ECM), and (iii) spherical colonies without ECM. All colony configurations were simulated using $N_{c}=41$ and pigment concentrations from Culture B.

colonies (see Fig. 2d). Instead, Fig. 7 indicates a decrease in the normalized absorption cross-section of cells in spherical colonies with ECM due to increased reflection at the ECM/cell boundary. Similar results were obtained at other wavelengths. Despite these nuances, the overall effect of ECM was minor compared to the decrease in absorption crosssection due to changes in pigment concentration and mutual shading. Thus, the effect of the ECM can be considered negligible for most practical situations.

\subsubsection{Effect of pigment concentrations}

Fig. 8 plots the spectral average mass absorption cross-section $\bar{A}_{a b s, \lambda}$ as a function of wavelength over the PAR region obtained experimentally and predicted by the MCRT method for (i) single cells using pigment concentrations of Culture A, (ii) single cells using pigment concentrations of Culture B, (iii) fractal colonies without ECM, and (iv) spherical colonies without ECM. Since ECM had a negligible effect on $\bar{A}_{a b s, \lambda}$ as discussed previously, colonies with ECM are only shown in Supplementary Materials. All simulated colonies had total pigment concentration $C_{p i g}$ equal to that of Culture B and consisted of $N_{c}=41$ monodisperse cells. This value of $N_{c}$ was calculated by matching the average projected area of the colonies in Culture B with that of the simulated fractal aggregates. To do so, the average projected area of colonies in Culture B was estimated from microscope images of colonies. In addition, a power law fit of the projected area of the numerically generated fractal aggregates was performed as a function of $N_{c}$ (see Supplementary Material). First, Fig. 8 indicates that good agreement was obtained between the experimental measurements and model predictions of the spectral average mass absorption cross-section $\bar{A}_{a b s, \lambda}$ for single cells in Culture A. This served as further validation that the MCRT method can predict the absorption cross-section of a polydisperse suspension of single microalgae cells.

Moreover, Fig. 8 shows a notable decrease in the model predictions of $\bar{A}_{a b s, \lambda}$ obtained for single cells using the total pigment concentration $C_{\text {pig }}$ of Culture B compared with predictions using $C_{\text {pig }}$ of Culture A. Nonetheless, the decrease observed in the experimental data of $\bar{A}_{a b s, \lambda}$ between Culture A and Culture B was not entirely captured by the simulations considering the reduction in pigment concentration alone. However, for all colony configurations simulated with pigment concentrations of Culture $\mathrm{B}$, predictions of $\bar{A}_{a b s, \lambda}$ were smaller than for single cells. This establishes that, in addition to pigment concentrations, the physical arrangement of cells in the colonies contributed significantly to the reduction in their spectral orientation-averaged mass absorption cross-section $\bar{A}_{a b s, \lambda}^{c o}$. This was due to mutual shading between the cells. As discussed previously, the difference between the predicted values of $\bar{A}_{a b s, \lambda}$ for single cells and for cells in colonies was larger at wavelengths where the cell absorption index $k_{c, \lambda}$ was larger. However, the difference in $\bar{A}_{a b s, \lambda}^{c o}$ between the cells in the fractal colonies and those in the spherical shell colonies was minor at all wavelengths. Then, a detailed geometric description of the cell spatial distribution in the colonies is not essential.

\section{Conclusion}

This study provided a qualitative understanding and a quantitative assessment of the effect of pigment concentrations, colony spatial arrangement, and colony extracellular matrix (ECM) on the spectral orientation-averaged mass absorption cross-section $\bar{A}_{a b s, \lambda}^{c o}$ of $B$. braunii cells in colonies. First, experimental measurements established that colony formation can significantly decrease $\bar{A}_{a b s, \lambda}^{c o}$ across the PAR region. Then, simulations showed that a large part of the observed decrease was readily explained by a decrease in pigment concentrations. Additionally, the arrangement of cells in colonies was found to significantly contribute to the reduction of the spectral average mass absorption cross-section of $B$. braunii cells due to mutual shading among cells. Good agreement was found between predictions of $\bar{A}_{a b s, \lambda}^{c o}$ by the Monte Carlo ray tracing method for computationally generated fractal colonies and the volume and average projected area equivalent coated sphere approximation. Finally, the presence of ECM and the cell spatial distribution in the colony had negligible effects on the mass absorption cross-section $\bar{A}_{a b s, \lambda}^{c o}$ of cells in colonies.

\section{CRediT authorship contribution statement}

Jack Hoeniges: Methodology, Software, Validation, Investigation, Writing - original draft, Visualization. Razmig Kandilian: Conceptualization, Investigation, Resources. Chuanxin Zhang: Methodology, Software. Jeremy Pruvost: Writing - review \& editing. Jack Legrand: Writing - review \& editing. Dominique Grizeau: Writing - review \& editing. Laurent Pilon: Conceptualization, Writing - review \& editing, Supervision.

\section{Declaration of competing interest}

The authors declare that they have no known competing financial interests or personal relationships that could have appeared to influence the work reported in this paper.

\section{Acknowledgement}

This research was supported in part by the U.S. National Science Foundation under the NRT-INFEWS: Integrated Urban Solutions for Food, Energy, and Water Management (Grant No. DGE-1735325). The authors would also like to acknowledge the International Research Network (ex-GDRI) WONDER (World Oilalg Network for Design of Processes and Strains for Elaboration of Renewable Energy from Microalgae) of the French Centre National de la Recherche Scientifique (CNRS) for its support. 


\section{Statement of informed consent, human/animal rights}

No conflicts, informed consent, or human or animal rights are applicable to this study.

\section{Appendix A. Supplementary data}

Supplementary data to this article can be found online at https:// doi.org/10.1016/j.algal.2020.101985.

\section{References}

[1] J.Y. An, S.J. Sim, J.S. Lee, B.W. Kim, Hydrocarbon production from secondarily treated piggery wastewater by the green alga Botryococcus braunii, J. Appl. Phycol, 15 (2-3) (2003) 185-191.

[2] Y. Shen, W. Yuan, Z. Pei, E. Mao, Culture of microalga Botryococcus in livestock wastewater, Trans. ASABE 51 (4) (2008) 1395-1400.

[3] A.R. Rao, R. Sarada, V. Baskaran, G.A. Ravishankar, Antioxidant activity of Botryococcus braunii extract elucidated in vitro models, J. Agric. Food Chem. 54 (13) (2006) 4593-4599.

[4] A.R. Rao, A.H. Reddy, S.M. Aradhya, Antibacterial properties of Spirulina platensis, Haematococcus pluvialis, Botryococcus braunii micro algal extract, Curr. Trends Biotechnol. Pharm. 4 (3) (2010) 809-819.

[5] L. Custódio, F. Soares, H. Pereira, M.J. Rodrigues, L. Barreira, A.P. Rauter, F. Alberício, J. Varela, Botryococcus braunii and Nannochloropsis oculata extracts inhibit cholinesterases and protect human dopaminergic SH-SY5Y cells from $\mathrm{H}_{2} \mathrm{O}_{2}$ induced cytotoxicity, J. Appl. Phycol. 27 (2) (2015) 839-848.

[6] A. Banerjee, R. Sharma, Y. Chisti, U.C. Banerjee, Botryococcus braunii: a renewable source of hydrocarbons and other chemicals, Crit. Rev. Biotechnol. 22 (3) (2002) 245-279.

[7] J. Jin, C. Dupré, J. Legrand, D. Grizeau, Extracellular hydrocarbon and intracellular lipid accumulation are related to nutrient-sufficient conditions in $\mathrm{pH}$-controlled chemostat cultures of the microalga Botryococcus braunii SAG 30.81, Algal Res. 17 (2016) 244-252.

[8] C. Largeau, E. Casadevall, C. Berkaloff, P. Dhamelincourt, Sites of accumulation and composition of hydrocarbons in Botryococcus braunii, Phytochemistry 19 (6) (1980) 1043-1051.

[9] J. Jin, C. Dupré, K. Yoneda, M.M. Watanabe, J. Legrand, D. Grizeau, Characteristics of extracellular hydrocarbon-rich microalga Botryococcus braunii for biofuels production: recent advances and opportunities, Process Biochem. 51 (11) (2016) $1866-1875$.

[10] M. Kanda, A. Nakamura, H. Iwamoto, S. Konosu, Lipid composition of a green alga, Botryococcus braunii, Agric. Biol. Chem. 51 (2) (1987) 493-498.

[11] B. Moutel, M. André, D. Kucma, J. Legrand, D. Grizeau, J. Pruvost, O. Gonçalves, Assessing the biofuel production potential of Botryococcus braunii strains by sensitive rapid qualitative chemotyping using chemometrically-assisted gas chromatography-mass spectrometry, Algal Res. 11 (2015) 33-42.

[12] B. Sadeghin, M.H. Sarrafzadeh, J. Jin, C. Dupré, M.M. Watanabe, J. Legrand, D. Grizeau, Variation of fatty acids composition in the hydrocarbon produce Botryococcus braunii BOT 22, Biomass Bioenergy 119 (2018) 456-461.

[13] H. Watanabe, D. Li, Y. Nakagawa, K. Tomishige, K. Kaya, M.M. Watanabe, Characterization of oil-extracted residue biomass of Botryococcus braunii as a biofuel feedstock and its pyrolytic behavior, Appl. Energy 132 (2014) 475-484.

[14] T.L. Weiss, R. Roth, C. Goodson, S. Vitha, I. Black, P. Azadi, J. Rusch, A. Holzenburg, T.P. Devarenne, U. Goodenough, Colony organization in the green alga Botryococcus braunii (Race B) is specified by a complex extracellular matrix, Eukaryot. Cell 11 (12) (2012) 1424-1440.

[15] J. Pruvost, J.-F. Cornet, L. Pilon, Large-scale production of algal biomass: photobioreactors, in: F. Bux, Y. Chisti (Eds.), Algae Biotechnology: Products and Processes, Springer International Publishing, Switzerlands, 2016, pp. 41-66.

[16] J. Pruvost, J.-F. Cornet, Knowledge models for the engineering and optimization of photobioreactors, in: C. Posten, W. Christian (Eds.), Microalgal Biotechnology: Potential and Production, De Gruyter, Berlin, DE, 2012, pp. 181-224 chapter 10.

[17] A. Souliès, J. Legrand, H. Marec, J. Pruvost, C. Castelain, T. Burghelea, J.-F. Cornet, Investigation and modeling of the effects of light spectrum and incident angle on the growth of Chlorella vulgaris in photobioreactors, Biotechnol. Prog. 32 (2) (2016) 247-261.

[18] E. Lee, J. Pruvost, X. He, R. Munipalli, L. Pilon, Design tool and guidelines for outdoor photobioreactors, Chem. Eng. Sci. 106 (2014) 18-29.

[19] J.F. Cornet, C.G. Dussap, G. Dubertret, A structured model for simulation of cultures of the cyanobacterium Spirulina platensis in photobioreactors: I. Coupling between light transfer and growth kinetics, Biotechnol. Bioeng. 40 (7) (1992) 817-825.

[20] L. Pottier, J. Pruvost, J. Deremetz, J.-F. Cornet, J. Legrand, C.-G. Dussap, A fully predictive model for one-dimensional light attenuation by Chlamydomonas reinhardtii in a torus photobioreactor, Biotechnol. Bioeng. 91 (2005) 569-582.

21] R. Kandilian, A. Soulies, J. Pruvost, B. Rousseau, J. Legrand, L. Pilon, Simple method for measuring the spectral absorption cross-section of microalgae, Chem. Eng. Sci. 146 (2016) 357-368.

[22] L. Liu, M.I. Mishchenko, P.W. Arnott, A study of radiative properties of fractal soot aggregates using the superposition T-matrix method, J. Quant. Spectrosc. Radiat. Transf. 109 (15) (2008) 2656-2663.

[23] C.M. Sorensen, Light scattering by fractal aggregates: a review, Aerosol Sci.
Technol. 35 (2) (2001) 648-687.

[24] R. Kandilian, R.L. Heng, L. Pilon, Absorption and scattering by fractal aggregates and by their equivalent coated spheres, J. Quant. Spectrosc. Radiat. Transf. 151 (2015) 310-326.

[25] G.W. Mulholland, C.F. Bohren, K.A. Fuller, Light scattering by agglomerates: coupled electric and magnetic dipole method, Langmuir 10 (8) (1994) 2533-2546.

[26] L. Liu, M.I. Mishchenko, Scattering and radiative properties of complex soot and soot-containing aggregate particles, J. Quant. Spectrosc. Radiat. Transf. 106 (2007) $262-273$.

[27] F. Liu, D.R. Snelling, G.J. Smallwood, Effects of the fractal prefactor on the optica properties of fractal soot aggregates, Proceedings of the ASME Micro/Nanoscale Heat and Mass Transfer International Conference 2009, Shanghai, China, vol. 2 , ASME, 2009, pp. 363-371.

[28] F. Liu, C. Wong, D.R. Snelling, G.J. Smallwood, Investigation of absorption and scattering properties of soot aggregates of different fractal dimension at $532 \mathrm{~nm}$ using RDG and GMM, Aerosol Sci. Technol. 47 (12) (2013) 1393-1405.

[29] B. Moutel, O. Gonçalves, F. Le Grand, M. Long, P. Soudant, J. Legrand, D. Grizeau, J. Pruvost, Development of a screening procedure for the characterization of Botryococcus braunii strains for biofuel application, Process Biochem. 51 (11) (2016) 1855-1865.

[30] K.C. Díaz Bayona, L.A. Garcés, Effect of different media on exopolysaccharide and biomass production by the green microalga Botryococcus braunii, J. Appl. Phycol. 26 (5) (2014) 2087-2095.

[31] K. Zhang, E. Kojima, Effect of light intensity on colony size of microalga Botryococcus braunii in bubble column photobioreactors, J. Ferment. Bioeng. 86 (6) (jan 1998) 573-576.

[32] B. Moutel, Etude de la mircoalgue Botryococcus braunii en vue d'une application aux bioaérocarburants, PhD thesis Université de Nantes, Nantes, France, 2014 (in French).

[33] R.J. Ritchie, Consistent sets of spectrophotometric chlorophyll equations for acetone, methanol and ethanol solvents, Photosynth. Res. 89 (1) (2006) 27-41.

[34] O. Blifernez-Klassen, S. Chaudhari, V. Klassen, R. Wördenweber, T. Steffens, D. Cholewa, K. Niehaus, J. Kalinowski, O. Kruse, Metabolic survey of Botryococcus braunii: impact of the physiological state on product formation, PLoS One 13 (6) (2018) 1-23.

[35] R.G. Barlow, J. Aiken, G.F. Moore, P.M. Holligan, S. Lavender, Pigment adaptation in surface phytoplankton along the eastern boundary of the Atlantic Ocean, Mar. Ecol. Prog. Ser. 281 (2004) 13-26.

[36] J.D.H. Strickland, T.R. Parsons, A Practical Handbook of Seawater Analysis, 2nd edition, Fisheries Research Board of Canada, Ottawa, 1968.

[37] M.I. Mishchenko, L.D. Travis, Light scattering by polydispersions of randomly oriented spheroids with sizes comparable to wavelengths of observation, Appl. Opt. 33 (30) (1994) 7206

[38] R. Kandilian, J. Pruvost, A. Artu, C. Lemasson, J. Legrand, L. Pilon, Comparison of experimentally and theoretically determined radiation characteristics of photosynthetic microorganisms, J. Quant. Spectrosc. Radiat. Transf. 175 (2016) 30-45.

[39] L. Pilon, H. Berberoğlu, R. Kandilian, Radiation transfer in photobiological carbon dioxide fixation and fuel production by microalgae, J. Quant. Spectrosc. Radiat. Transf. 112 (17) (2011) 2639-2660.

[40] L. Pilon, R. Kandilian, Interaction between light and photosynthetic microorganisms, in: J. Legrand (Ed.), Advances in Chemical Engineering, vol. 48, Academic Press, Cambridge, MA, 2016, pp. 107-149 chapter 2.

[41] H. Berberoğlu, P.S. Gomez, L. Pilon, Radiation characteristics of Botryococcus braunii, Chlorococcum littorale, and Chlorella sp. used for $\mathrm{CO}_{2}$ fixation and biofuel production, J. Quant. Spectrosc. Radiat. Transf. 110 (17) (2009) 1879-1893.

[42] E. Lee, R.L. Heng, L. Pilon, Spectral optical properties of selected photosynthetic microalgae producing biofuels, J. Quant. Spectrosc. Radiat. Transf. 114 (2013) $122-135$

[43] R. Kandilian, E. Lee, L. Pilon, Radiation and optical properties of Nannochloropsis oculata grown under different irradiances and spectra, Bioresour. Technol. 137 (2013) 63-73.

[44] R. Kandilian, J. Pruvost, J. Legrand, L. Pilon, Influence of light absorption rate by Nannochloropsis oculata on triglyceride production during nitrogen starvation, Bioresour. Technol. 163 (2014) 308-319.

[45] A. Bhowmik, L. Pilon, Can spherical eukaryotic microalgae cells be treated as optically homogeneous? J. Opt. Soc. Am. A 33 (8) (2016) 1495-1503.

[46] I.D. Nikolov, C.D. Ivanov, Optical plastic refractive measurements in the visible and the near-infrared regions, Appl. Opt. 39 (13) (2000) 2067.

[47] O. Zhernovaya, O. Sydoruk, V. Tuchin, A. Douplik, The refractive index of human hemoglobin in the visible range, Phys. Med. Biol. 56 (13) (2011) 4013-4021.

[48] H.C. Van De Hulst, Light Scattering by Small Particles, 5th edition, Dover Publications, Inc, Mineola, NY, 1981.

[49] R.R. Bidigare, M.E. Ondrusek, J.H. Morrow, D.A. Kiefer, In-vivo absorption properties of algal pigments, in: R.W. Spinrad (Ed.), SPIE Proceedings, vol. 1302, Ocean Optics X, Orlando, FL, 1990, pp. 290-302.

[50] G.A. Jackson, R. Maffione, D.K. Costello, A.L. Alldredge, B.E. Logan, H.G. Dam, Particle size spectra between $1 \mu \mathrm{m}$ and $1 \mathrm{~cm}$ at Monterey Bay determined using multiple instruments, Deep-Sea Res. I: Oceanogr. Res. Pap. 44 (11) (1997) 1739-1767.

[51] K. Skorupski, J. Mroczka, T. Wriedt, N. Riefler, A fast and accurate implementation of tunable algorithms used for generation of fractal-like aggregate models, Phys. A Stat. Mech. Appl. 404 (2014) 106-117.

[52] A. Semechko, "Suite of Functions to Perform Uniform Sampling of a Sphere", https://github.com/AntonSemechko/S2-Sampling-Toolbox, Version 1.6.0.0, 2012.

[53] M. Satou, H. Yamaguchi, T. Murai, S. Yokoyama, Y. Sanada, A method of estimating the refractive index of hydrocarbons in coal derived liquids by a group contribution 
method, J. Jpn. Pet. Inst. 35 (6) (1992) 466-473.

[54] K. Zhu, L. Pilon, Transmittance of semitransparent windows with non-absorbing cap-shaped droplets condensed on their backside, J. Quant. Spectrosc. Radiat. Transf. 201 (2017) 53-63.

[55] K. Zhu, L. Pilon, Transmittance of semitransparent windows with absorbing capshaped droplets condensed on their backside, J. Quant. Spectrosc. Radiat. Transf. 201 (2017) 53-63.
[56] M.F. Modest, Radiative Heat Transfer, 3rd edition, Elsevier Inc, Oxford, UK, 2013.

[57] D.W. Mackowski, M.I. Mishchenko, A multiple sphere T-matrix Fortran code for use on parallel computer clusters, J. Quant. Spectrosc. Radiat. Transf. 112 (13) (2011) 2182-2192.

[58] H. Berberoğlu, L. Pilon, A. Melis, Radiation characteristics of Chlamydomonas reinhardtii CC125 and its truncated chlorophyll antenna transformants tla1, tlaX and tla1-CW+, Int. J. Hydrog. Energy 33 (22) (2008) 6467-6483. 